\title{
Development of a Multiaction Hybrid Damper for Passive Energy Dissipation
}

\author{
Ji-Eun Roh $\mathbb{D}^{1},{ }^{1}$ Moo-Won Hur, ${ }^{1}$ Hyun-Hoon Choi, ${ }^{2}$ and Sang-Hyun Lee $\mathbb{C}^{1}$ \\ ${ }^{1}$ Department of Architectural Engineering, Dankook University, Yongin, Republic of Korea \\ ${ }^{2}$ Heun Deul Lim Corporation, Seongnam, Republic of Korea \\ Correspondence should be addressed to Sang-Hyun Lee; lshyun00@dankook.ac.kr
}

Received 28 July 2017; Revised 11 December 2017; Accepted 2 January 2018; Published 31 January 2018

Academic Editor: Abdul Qadir Bhatti

Copyright (c) 2018 Ji-Eun Roh et al. This is an open access article distributed under the Creative Commons Attribution License, which permits unrestricted use, distribution, and reproduction in any medium, provided the original work is properly cited.

\begin{abstract}
A multiaction hybrid damper (MHD) is designed to have independent hysteretic characteristics under small and large loading conditions, and its control performance for building structures excited by wind or earthquake load is verified. The MHD is composed of steel elements, two friction pads, and two lead rubber bearings (LRBs). Because the friction pads and the LRBs are in series connection, only the LRBs deform before the friction pad slippage occurs. After the friction slippage, the damper deformation concentrates on the friction pads. The initial stiffness and hysteresis are dependent on the properties of the LRB, and the maximum force is determined by the friction pad. Accordingly, the load-deformation behaviors before/after the friction slippage can be independently designed to show optimal performance for a building structure subject to wind and earthquake loads. The cyclic loading tests of a full scale MHD were conducted to evaluate the multiaction behaviors and energy dissipation capacity of the MHD. The control performance of the MHD damper is analytically investigated by using a 20-story steel structure subject to wind loads and a 15-story RC structure excited by earthquake loads. The MHD damper showed good performance for reducing both the linear wind-induced and nonlinear earthquake-induced responses.
\end{abstract}

\section{Introduction}

A variety of research on developing passive dampers has been conducted for the purpose of reducing the earthquake- or wind-induced response of building structures. The passive dampers are classified as either displacement-dependent or velocity-dependent. Metallic yield or friction type damper is displacement-dependent because the force response is mainly a function of the relative displacement between each end of the device and is independent of the relative velocity or excitation frequency. Viscous or viscoelastic or mass type damper is velocity-dependent because the force response is primarily a function of the relative velocity and the properties vary according to the excitation frequency. Both the displacementdependent and the velocity-dependent dampers have been commonly used for the earthquake-resistant design while the velocity-dependent dampers have been generally used for the wind-resistant design.

The force-displacement mechanism of the metallic yield damper is based on elastic and plastic deformations of the metal such as steel. Added damping and stiffness (ADAS) consisting of multiple X-shaped steel plates was first introduced by Bergman. The ADAS uniformly distributes the yielding mechanism along the steel plate [1]. Other configurations of the metallic yield damper include triangular added damping and stiffness (TADAS), honeycomb, and slit dampers [2-4]. Metallic yield damper is inexpensive to manufacture and its yielding force can be easily modulated by changing the thickness or the number of the steel plates. The metallic damper, however, has some undesirable features such as permanent deformation after the steel yielding and no energy dissipation before the yielding. If the failure of the steel plate occurs during the event, the damper should be replaced by new one after the event.

Friction dampers dissipate structural energy through slippage mechanism between two elements and the slip force level can be easily adjusted by controlling the clamping force. The friction damper was proposed by Pall and Marsh and it was a device installed at the crossing joint of the Xbrace to avoid the compression in the brace member [5]. 


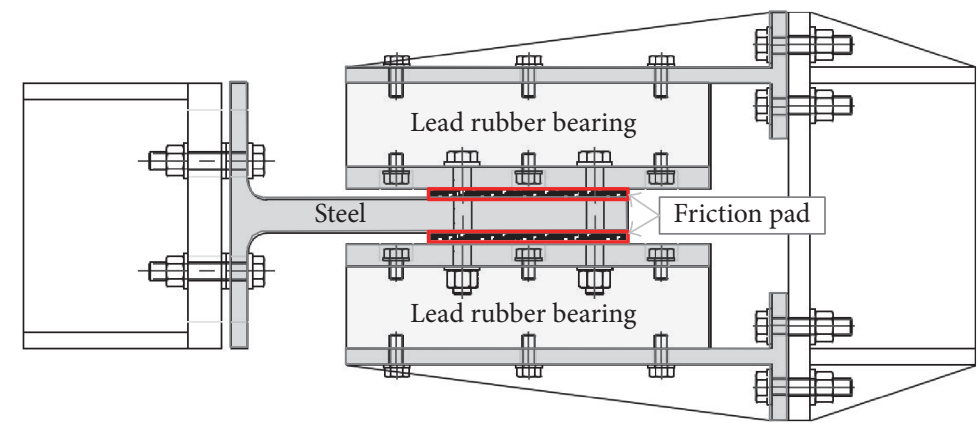

FIgURE 1: Section of the proposed MHD.

Two typical types of the friction dampers are rotational one proposed by Mualla [6] and slotted-bolted one proposed by FitzGerald et al. [7]. Friction dampers dissipate a lot of energy in comparison with other ones with the identical maximum force, since it generates rectangular hysteresis loops. In the design of the friction damper for improving seismic performance of building structures, it is the most important factor to determine the slip load of the damper and brace stiffness. Filiatrault and Cherry have developed design procedure for equally distributed friction dampers minimizing the sum of normalized displacements and dissipated energy through parametric study on the natural period of the structure, the frequency content of an earthquake, and the slip load of the friction damper [8]. Fu and Cherry proposed a design procedure of the friction dampers using a force normalization coefficient [9]. Lee et al. proposed the seismic design methodology of the friction dampers based on the story shear force distribution of a building structure [10].

Lead rubber bearing (LRB) proposed by Robinson was manufactured by drilling a hole through the center of the rubber plate and filling the hole with a lead insert. This material has viscoelastic characteristics of restoring and damping forces [11]. LRB is widely used for the seismic isolation installed at the base of the building.

General passive dampers utilize single material for achieving the energy dissipation mechanism and the capacity of the material governs the damper performance. The metallic or friction damper does not show any energy dissipation mechanism before yielding or slippage. Consequently, the metallic or friction damper is almost useless for small load which does not excite the structure over a specific loading level causing yielding or slippage of the dampers. On the other hand, the LRB has initial stiffness and damping, so the LRB can be used under both the small and large loading conditions. However, the LRB does not have larger energy dissipation during one cycle when compared with the friction or yield damper having rectangular hysteretic curve.

Recently, research on developing hybrid damper for wind and earthquake loads has been carried out. Hybrid passive control damper (HPCD) consisting of high-damping rubber damper in series with a buckling-restrained brace (BRB) was developed to dissipate multilevel seismic energy [12]. Christopoulos and Montgomery suggested that viscoelastic coupling damper (VCD) consists of VE material, steel plate, and anchor to reduce both the wind and earthquake response of tall shear wall buildings [13]. A hybrid damper which combines a friction damper and steel strip damper is proposed for improving the seismic performance of structures at multiple levels by Lee et al. [14].

In this study, a multiaction hybrid damper (MHD) is proposed to provide independent hysteretic characteristics for small and large loading conditions. The major components of the MHD are steel elements, two friction pads, and two lead rubber bearings. The lead rubber bearing and friction pad, respectively, govern the initial and subsequent hysteretic behaviors of the MHD for the small and large amplitudes of loading. The cyclic loading tests using a $200 \mathrm{kN}$ MHD were conducted for the verification of the damper performance. Also, numerical analyses were conducted for a 20-story steel building structure excited by wind load and a 15-story RC apartment structure under seismic load.

\section{Configuration and Mechanism of the MHD}

The MHD consists of three main parts, steel plates, two LRBs, and two friction pads as shown in Figure 1. Three T-shaped angles and two steel plates are used for connecting the LRBs and friction pads. All the steel elements are manufactured by using rolled section for cost reduction of the MHD. Clamping force of the friction pad is controlled by the number of the high-tensile bolts and torque applied to the bolts.

Figure 2(a) shows the configuration of the typical MHD, and Figure 2(b) is the MHD without LRBs. As shown in Figure 2(b), the MHD can be utilized as a simple friction damper if the LRB is not used and the steel plates on friction pads are directly connected to the T-shaped angle. When the considered load is large enough to cause the slippage of the friction damper and the additional damping is not required for small load, the MHD can be used as a friction damper for economical efficacy.

Figure 3 illustrates the mechanism of the MHD. The steel plates, the LRBs, and the friction pads are in series connection with regard to the horizontal axis movement. If the slippage in the friction pad does not occur, only the LRB and steel element deform. Particularly, when the stiffness of the steel element is comparatively larger to that of the LRB, the initial 
TABLE 1: Slip load according to the number of bolts and tightening torque.

\begin{tabular}{lcccc}
\hline $\begin{array}{l}\text { The number of } \\
\text { high-tensile bolts }\end{array}$ & $\begin{array}{c}\text { Tightening torque per bolt, } \\
T(\mathrm{~N} \cdot \mathrm{m})\end{array}$ & $\begin{array}{c}\text { Tension per bolt, } F \\
(\mathrm{kN})\end{array}$ & $\begin{array}{c}\text { Slip load per bolt, } \\
R(\mathrm{kN})\end{array}$ & $\begin{array}{c}\text { Slip load } \\
(\mathrm{kN})\end{array}$ \\
\hline 4 & 60 & 20.9 & 23.0 & 91.9 \\
4 & 120 & 41.8 & 46.0 & 183.9 \\
8 & 60 & 20.9 & 23.0 & 183.9 \\
8 & 120 & 41.8 & 46.0 \\
\hline
\end{tabular}

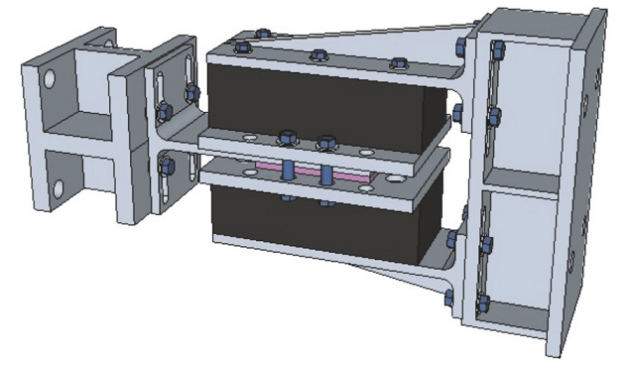

(a) Typical MHD

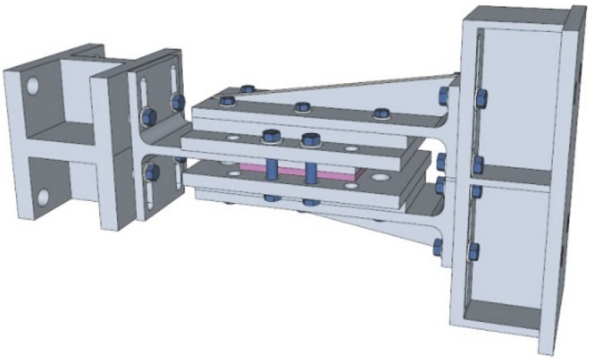

(b) MHD without LRBs

Figure 2

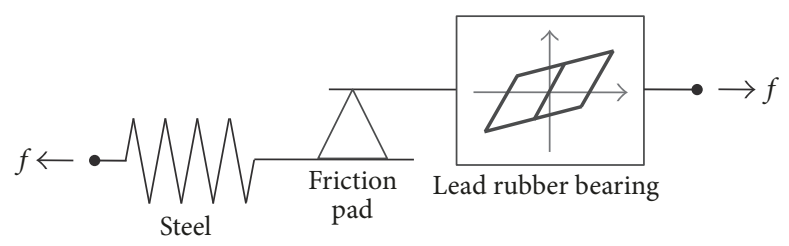

FIgURE 3: Mechanism of the MHD.

deformation induced by the external force $f$ mainly concentrates on the LRB. The damper ends shall be connected to the structural system such as brace or beam or column. When the force level generated by the LRB reaches the maximum static frictional force of the friction pads, the slippage of the friction pads occurs and all the subsequent deformation concentrates on the friction pads. This implies that the initial deformation and energy dissipation are governed by the LRB while the subsequent deformation and maximum force are dependent on the friction pads.

\section{Experimental Study}

3.1. Slip Load of the Friction Pad. The slip load of the friction pad is dependent on normal clamping force, which is determined by the number of the high-tensile bolts and their tightening torques applied to the bolts. ASTM A490-M16 (with $16 \mathrm{~mm}$ diameter and $2 \mathrm{~mm}$ pitch) bolts were used for the connections. Formula (1) is interaction between slip load $(R)$ and normal force $(F)$.

$$
R=\mu \times h_{s c} \times F \times N_{s},
$$

where $\mu$ is a friction coefficient between the friction pad and the steel plate; $h_{s c}$ is a factor depending on the shape of the bolt hole; $N_{s}$ is the number of slip planes; $h_{s c}$ is 1.0 for standard bolt hole; and $N_{s}=2$ are used in the MHD.
The normal force $F$ is determined by tightening torque (T) based on the following [15].

$$
F=T \times \frac{1}{0.161 p+0.583 d_{m} \times k_{1}+0.5 D_{k} \times k_{2}},
$$

where $T$ is tightening torque $(N \cdot m), p$ is screw pitch, $d_{m}$ is average diameter of the screw, $k_{1}$ is friction coefficient between threads of bolt and nut, and $D_{k}$ and $k_{2}$ are, respectively, the average diameter and friction coefficient between head of the bolt and contacted nut. Table 1 shows the calculated slip load with regard to the number of high-tensile bolts and tightening torque.

3.2. Test of the MHD without the LRB. The cyclic loading tests on the MHD without the LRB were first conducted in order to investigate the characteristics of frictional behavior of the MHD. The test configuration is shown in Figure 4. Two reaction frames were used for the installation of the hydraulic actuator and the damper, and the actuator controls the movement of the one end of the damper. A hydraulic actuator with maximum loading capacity $250 \mathrm{kN}$ and $150 \mathrm{~mm}$ stroke was used.

The cyclic loading tests were carried out with variables of the number of high-tensile bolts and tightening torques. The maximum displacement was $5 \mathrm{~mm}$, and the excitation frequency was $0.1 \mathrm{~Hz}$. Figure 5(a) shows the force-displacement 


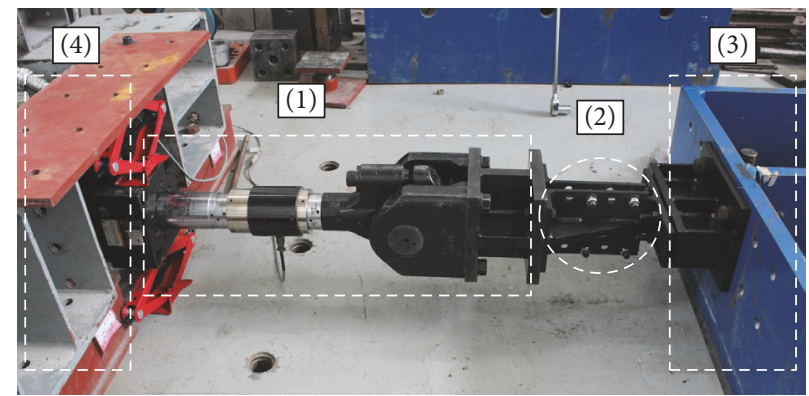

FIgURE 4: Test configuration; (1) hydraulic actuator, (2) the MHD without the LRB, and (3) and (4) reaction frames.

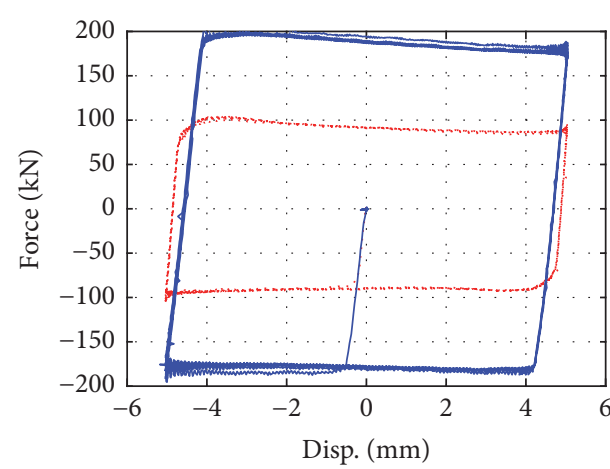

Bolt 4EA

- Bolt 8EA

(a)

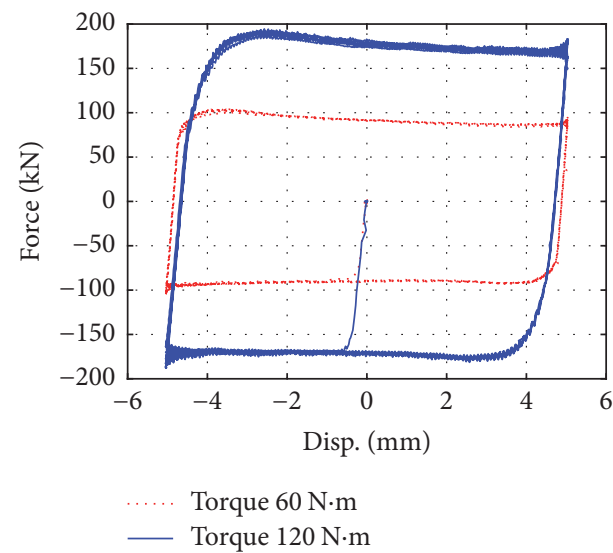

(b)

FIGURE 5: Force-displacement curves of the MHD without the lead rubber bearing; friction variation according to (a) the number of hightensile bolts and (b) tightening torques.
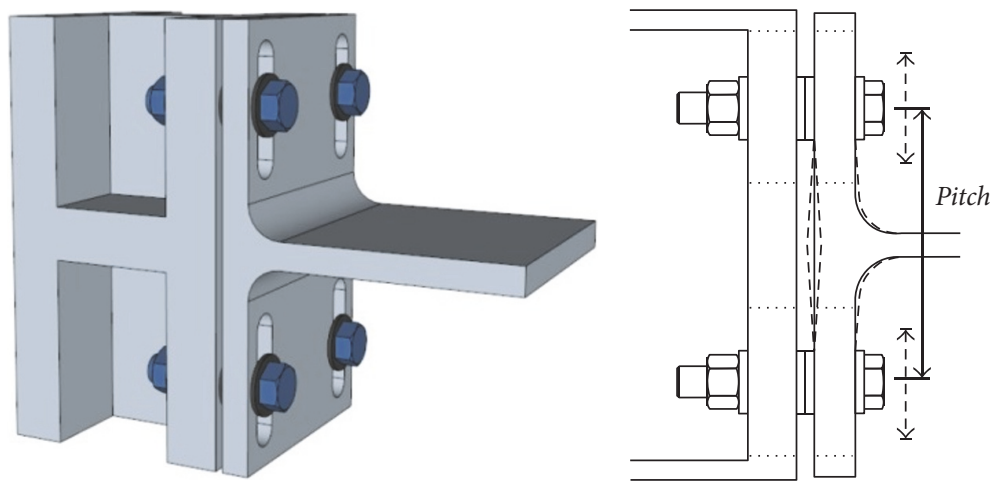

Figure 6: The bolt pitch in the T-shaped element.

curve obtained by using the specimens with 4 bolts and 8 bolts. The tightening torque of $60 \mathrm{~N} \cdot \mathrm{m}$ was applied to each bolt. The friction pad slip occurred at $94 \mathrm{kN}$ with 4 friction bolts and at $188 \mathrm{kN}$ with 8 friction bolts. The slip load increased in proportion to the number of high-tensile bolts. Another test was carried out by doubling the torque from $60 \mathrm{~N} \cdot \mathrm{m}$ to $120 \mathrm{~N} \cdot \mathrm{m}$ for the specimen with 4 bolts. Figure 5(b) shows that the slip load increased from $94 \mathrm{kN}$ to $188 \mathrm{kN}$ with increasing the torque.

The initial stiffness of the MHD without the LRB can be controlled by varying the pitches on the flange of the
T-shaped steel element as shown in Figure 6. The initial stiffness and the slip load of the MHD can be independently determined. The flange of the T-shaped element used in the experiment has $21 \mathrm{~mm}$ of thickness and $140 \mathrm{~mm}$ of width; the flexural stiffness of the hinge supported beam with concentrated load at midspan, $48 E I / l^{3}$, was used.

As shown in Figure 7, changes in initial stiffness were experimentally evaluated for the different pitches of $90 \mathrm{~mm}$, $150 \mathrm{~mm}$, and $200 \mathrm{~mm}$. Figure 8 shows the force-displacement curves obtained from the three specimens with different bolt pitches. It is observed that the initial stiffness decreases with 

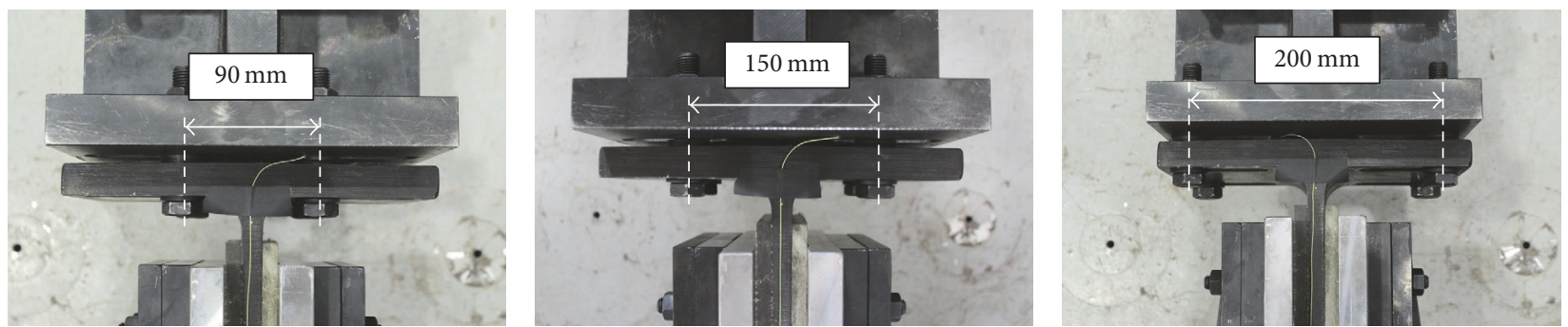

FIGURE 7: Three specimens with different bolt pitches.

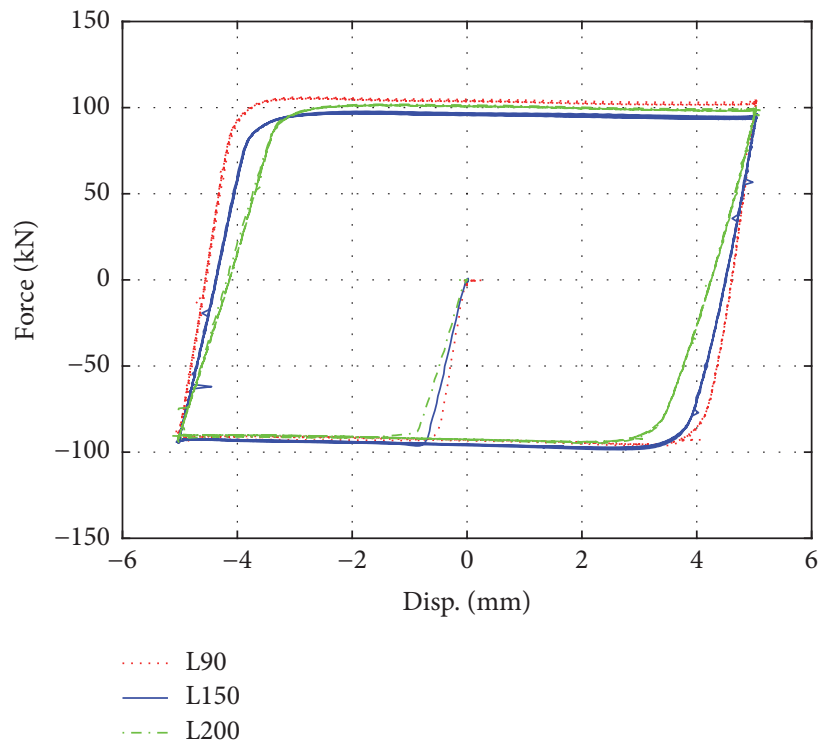

FIGURE 8: Force-displacement curves of the three specimens with different bolt pitches.
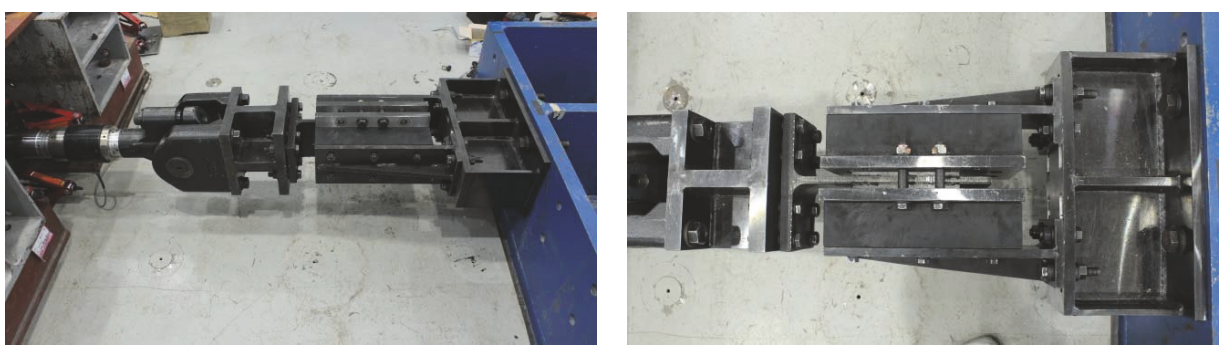

FIgURE 9: Cyclic loading tests of the typical MHD.

increasing pitches. From Table 2, it is noted that the calculated initial stiffness is very close to them from the experiments. The slip loads for all the cases are almost identical.

3.3. Test of the Typical MHD with the LRB. The hysteretic curves of the typical MHD with the LRB were obtained by conducting the cyclic loading tests as shown in Figure 9. In order to investigate the displacement-dependent characteristics of the MHD, force-displacement curves were obtained by changing the amplitude of the peak displacement.

Figure 10 shows the force-displacement curves under displacement-controlled cyclic loads with amplitudes of
$3 \mathrm{~mm}, 5 \mathrm{~mm}$, and $10 \mathrm{~mm}$ displacement. The friction pad was clamped by using the 4 high-tensile bolts fastened with torque $120 \mathrm{~N} \cdot \mathrm{m}$. The loading frequency was $0.1 \mathrm{~Hz}$ and 5 cycle tests were conducted. It is observed that the slip of the friction did not occur and only the LRB deformed. The maximum values of the restoring force induced by the LRB were about $50 \mathrm{kN}$, $70 \mathrm{kN}$, and $100 \mathrm{kN}$ for the amplitudes of $3 \mathrm{~mm}, 5 \mathrm{~mm}$, and $10 \mathrm{~mm}$, respectively. Because the restoring force of the LRB did not reach the slip load of the friction pad, the hysteretic characteristics of the MHD were determined only by the LRB. Table 3 shows the positive and negative force levels at the zero or $10 \mathrm{~mm}$ displacement per each cycle. All the values are within an error of $10 \%$, which implies that the deviation 
TABLE 2: Initial stiffness according to different pitches of bolts on the flange of the T-steel.

\begin{tabular}{|c|c|c|c|c|}
\hline \multirow{2}{*}{$\begin{array}{l}\text { Pitches of bolts on the } \\
\text { flange of the T-steel (mm) }\end{array}$} & \multirow{2}{*}{ Net length of bolts (mm) } & \multicolumn{2}{|c|}{ Initial stiffness (kN/mm) } & \multirow{2}{*}{ Error rate (\%) } \\
\hline & & Calculated & Experiment & \\
\hline 90 & 60 & 210.6 & 211.92 & 0.6 \\
\hline 150 & 120 & 162.1 & 161.89 & 0.1 \\
\hline 200 & 170 & 109.1 & 110.08 & 0.9 \\
\hline
\end{tabular}

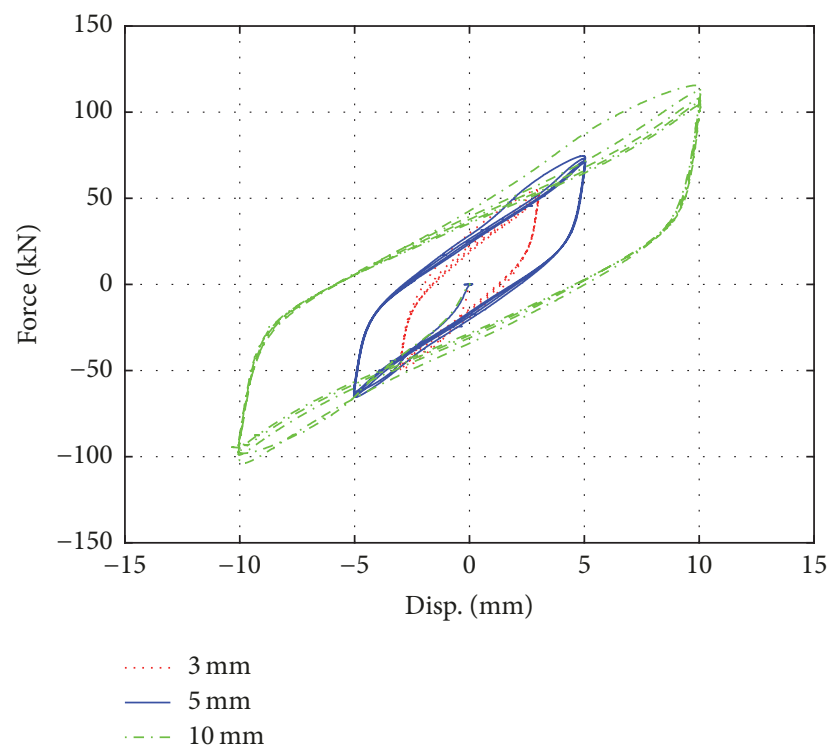

FIGURE 10: Force-displacement curves of the typical MHD for small deformation.

from the average value is small and the LRB has stable hysteretic characteristics. Because the friction pad and the LRB are in series connection, only the LRB deforms when the displacement is small and the restoring force of the LRB is not large enough to cause the slippage of the friction pad.

Another test was conducted when the slip load of the friction pad was reduced to about $100 \mathrm{kN}$ by loosening the torque to $60 \mathrm{~N} \cdot \mathrm{m}$. And then the peak displacement of the cyclic loading was set to be $40 \mathrm{~mm}$. The curve shown in Figure 11 with legend " $40 \mathrm{~mm}$ " is the result. The initial stiffness and hysteresis obtained within the displacement smaller than about $10 \mathrm{~mm}$ are identical to those of the LRB. When the restoring force reached about $100 \mathrm{kN}$, the slippage of the friction pad started and the force level with increasing displacement is almost constant, which is the typical characteristics of a friction damper. When the slippage of the friction pad occurred, the LRB did not show any deformation, which implies that the large deformation behavior of the typical MHD is governed by the friction pad. The curve shown in Figure 11 with legend " $60 \mathrm{~mm}$ " is the results from test conducted by doubling the torque from $60 \mathrm{~N} \cdot \mathrm{m}$ to $120 \mathrm{~N} \cdot \mathrm{m}$ and increasing the peak displacement to $60 \mathrm{~mm}$. It is identified that the slip load increases to about $200 \mathrm{kN}$ and the slippage the friction pad occurs at $14.1 \mathrm{~mm}$. Also, the energy dissipation per cycle increases by the increase of the slip load and the maximum displacement. Table 4 shows the forces at

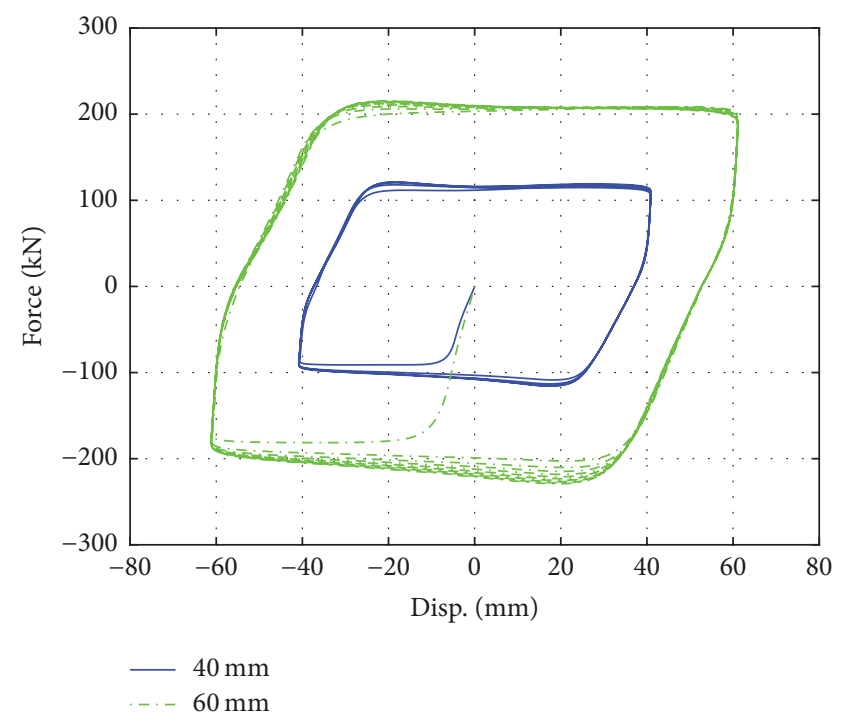

FIGURE 11: Force-displacement curves of the typical MHD for large deformation.

the zero or $60 \mathrm{~mm}$ displacement of the MHD. The maximum deviation from average value is just $6.8 \%$, which implies that the MHD has the stable hysteresis for the repeated loadings.

Table 5 shows the energy dissipated by the MHD per each loading cycle. The average of the dissipated energy increased significantly from $1238.5 \mathrm{kN} \cdot \mathrm{m}$ to $41743.6 \mathrm{kN} \cdot \mathrm{m}$ by increasing the peak displacement and force. The deviation from average was maximum $11.4 \%$ at the first cycle of the loading tests. After the first cycle, the deviation decreased and the MHD showed stable hysteresis.

\section{Application of the MHD for Wind Vibration Mitigation}

4.1. Structural Outline of a 20-Story Steel Structure. In order to evaluate the vibration control performance of the MHD for a building structure under wind loads, numerical analysis was conducted using a 20-story steel structure. The building is designed according to Korean Building Code (KBC2016) [15]. The building is supposed to be constructed in Seoul and it has $58.6 \mathrm{~m}$ height and $24 \mathrm{~m} \times 18 \mathrm{~m}$ plan. The used materials are SS400 for beams and SM490 for girder and column. MIDAS GEN was used as a design and analysis program [16]. The slab is modeled as a rigid diaphragm, and Figure 12 shows plan and elevation. 


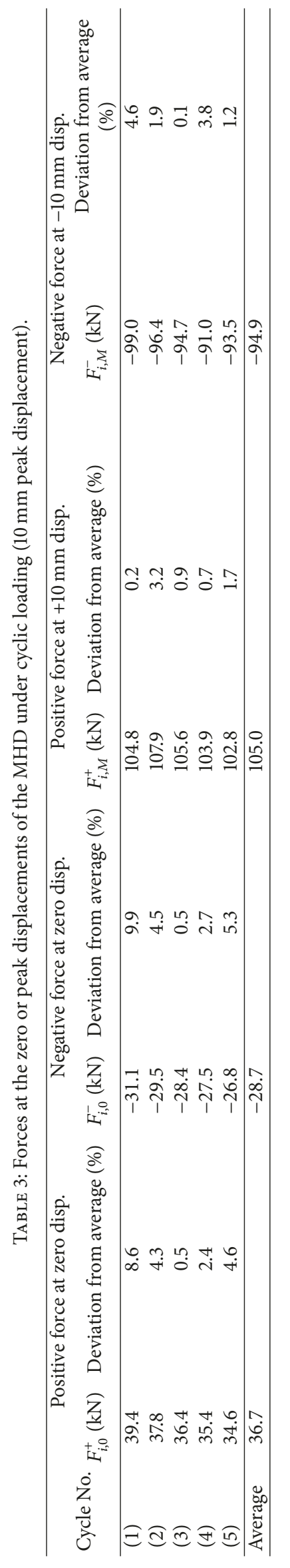




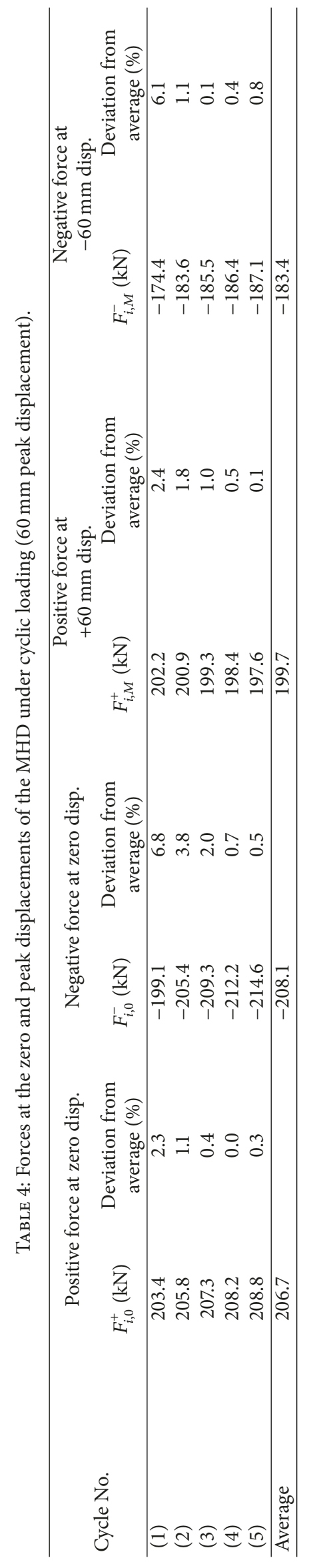


TABLE 5: Dissipated energy per each loading cycle.

\begin{tabular}{|c|c|c|c|c|}
\hline \multirow[t]{2}{*}{ Cycle number } & \multicolumn{2}{|c|}{$\begin{array}{l}10 \mathrm{~mm} \text { peak displacement } \\
\text { (about } 100 \mathrm{kN} \text { peak force) }\end{array}$} & \multicolumn{2}{|c|}{$\begin{array}{l}60 \mathrm{~mm} \text { peak displacement } \\
\text { (about } 200 \mathrm{kN} \text { peak force) }\end{array}$} \\
\hline & Dissipated energy $(\mathrm{N} \cdot \mathrm{m})$ & Deviation from average (\%) & Dissipated energy $(\mathrm{N} \cdot \mathrm{m})$ & Deviation from average (\%) \\
\hline$(1)$ & 1362.3 & 11.4 & 39152.4 & 7.9 \\
\hline (2) & 1261.6 & 3.1 & 41809.6 & 1.7 \\
\hline (3) & 1217.1 & 0.5 & 42531.7 & 0.0 \\
\hline$(4)$ & 1187.0 & 2.9 & 42618.0 & 0.2 \\
\hline$(5)$ & 1164.4 & 4.8 & 42706.4 & 0.4 \\
\hline Average & 1238.5 & & 41763.6 & \\
\hline
\end{tabular}

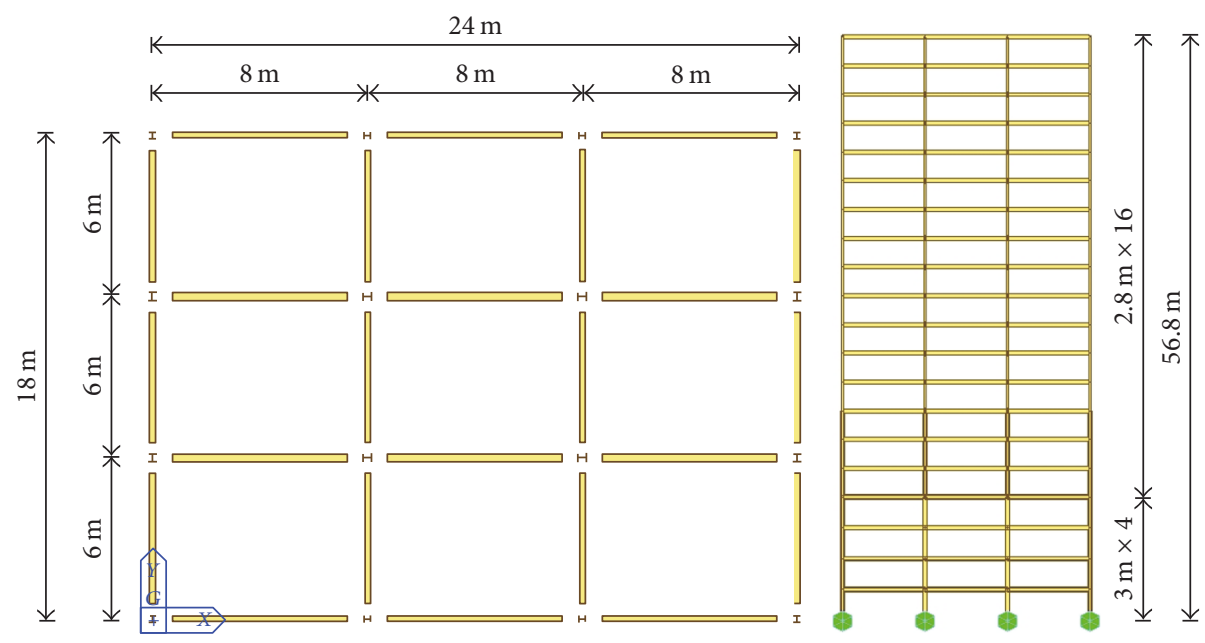

FIGURE 12: Plan and elevation of a 20-story steel structure.

4.2. Modal Analysis and Wind Load Generation. Figure 13 shows the first 3 mode shapes. The period of the first mode in $X$-direction was $4.14 \mathrm{sec}$., $4.34 \mathrm{sec}$. in $Y$ direction, and $3.75 \mathrm{sec}$. in torsion. The $1 \%$ modal damping ratio was used for all modes, and the only the fluctuation component in $X$ directional response was considered. The fluctuation component of the along-wind load was generated by using the method proposed by Wu et al. [17]. The method is to generate the time histories of along-wind loads based on the crosspower spectrum of the story wind loads. Figure 14 shows the time histories of the generated wind loads, and Figure 15 shows the wind-induced peak interstory drifts of the 20-story steel structure without the MHD. It is noted that the peak interstory drift is smaller than $13 \mathrm{~mm}$ at which the slippage of the friction occurs. Accordingly, if the $200 \mathrm{kN}$ MHD shown in Figure 11 is used, only the lead rubber bearing plays a role of dissipating energy, and the slippage of the friction pad is not expected.

4.3. Preliminary Design of the MHD. In this section, the MHD is preliminarily designed by using the concept of the equivalent damping ratio added by the MHD and gust factor. The gust factor for the flexible structure is given as [15]

$$
G_{f}=1+g_{f} \cdot \gamma_{f} \sqrt{B_{f}+R_{f}},
$$

where $g_{f}$ is peak factor, $\gamma_{f}$ is coefficient of variation of wind speed, $B_{f}$ s nonresonance factor, and $R_{f}$ is resonance factor

The peak and resonance factors are related with the structural damping ratio. Also, in gust factor, 1 is related with the mean component of the wind load and the remainder is related with the fluctuation component. Accordingly, the reduction ratio of the fluctuation component in the gust factor with regard to the increase of the damping ratio is given by

$$
\mathrm{RF}_{f, D}=\frac{G_{f}\left(\xi_{0}\right)-1}{G_{f}\left(\xi_{0}+\xi_{\alpha}\right)-1},
$$

where $\xi_{0}$ is the damping ratio of the original structure and $\xi_{\alpha}$ is damping ratio added by the damper.

Figure 16 shows the variation of $\mathrm{RF}_{f, D}$ with regard to $\xi_{\alpha}$. It is observed that $\mathrm{RF}_{f, D}$ is decreasing with increasing $\xi_{\alpha}$.

If the effect of the damper can be expressed as an equivalent damping ratio added by the damper, the fluctuation component in along-wind directional response of a structure with the damper can be estimated by simply multiplying $\mathrm{RF}_{f, D}$ and one structure without the damper. Added damping ratio, $\xi_{\alpha}$, by the damper is estimated by the following [18].

$$
\xi_{\alpha}=\frac{\sum W_{j}}{4 \pi \sum W_{k}},
$$




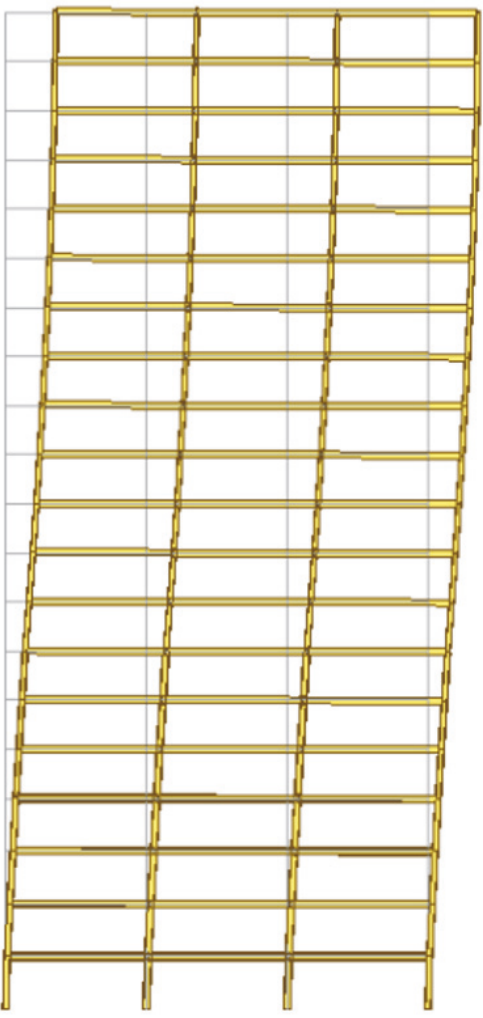

1st Modal Vibration in $X$ direction

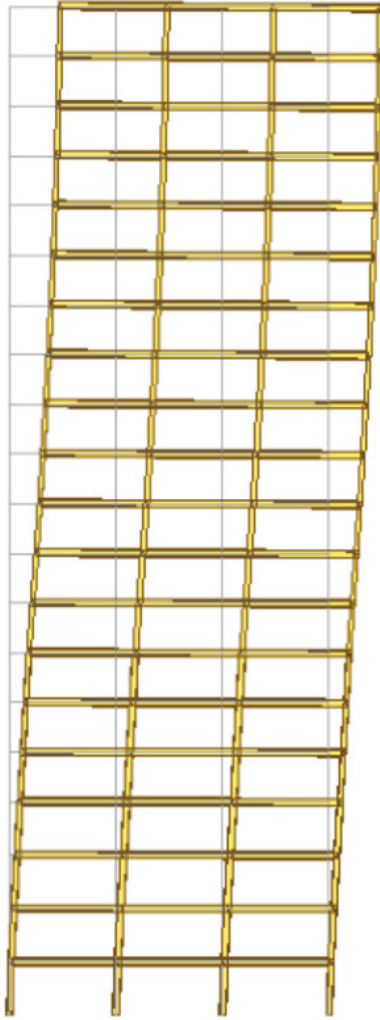

1st Modal Vibration in $Y$ direction

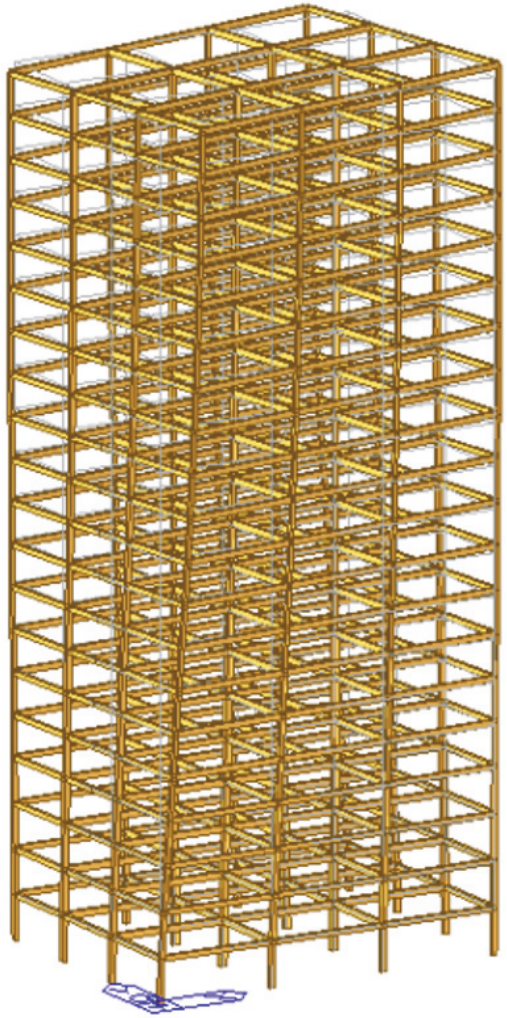

1st Modal Vibration in torsion

FIGURE 13: Mode shapes of a 20-story steel structure.

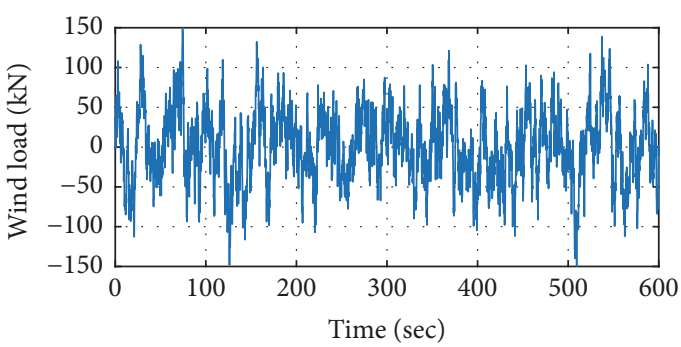

(a) Wind load applied to the 15th floor

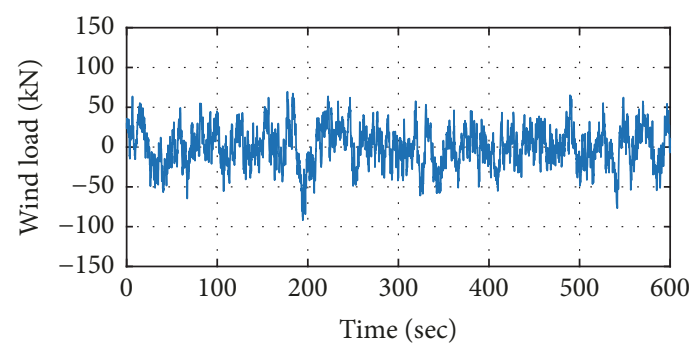

(b) Wind load applied to the 20th floor

Figure 14: Generated wind loads.

where $W_{j}$ is the work done by $j$ th damper during one complete cycle and $W_{k}$ is the maximum strain energy of the structure.

The hysteresis of the MHD shown in Figure 10 for small deformation can be idealized by using a bilinear curve as shown in Figure 17. Bilinear curve is represented by initial stiffness $k_{d 1}$, yield strength $f_{y}$, and postyield stiffness $k_{d 2} . \alpha$ is the postyield stiffness ratio to the initial stiffness, $D_{y}$ is the yield displacement, $D_{r}$ is the target displacement, and $\mu$ is the ratio of $D_{r}$ to $D_{y}$.

$\sum W_{k}$ is the sum of the strain energy of a structure itself and the strain energy due to the addition of the damping device by

$$
\sum W_{k}=\frac{1}{2} \sum_{i=1}^{N} F_{i} \cdot D_{i}+\frac{1}{2} \sum_{j=1}^{N_{d}} K_{\mathrm{eqj}} \cdot D_{r j}{ }^{2},
$$

where $N$ is the number of building stories, $F_{i}$ is $i$ th story wind load, $D_{i}$ is $i$ th story displacements, $N_{d}$ is the number of the dampers, $D_{r j}$ is the relative displacement between two ends of the $j$ th damper, and $K_{\text {eqj }}$ shall be taken by the following equation, as the equivalent stiffness of the damper.

$$
K_{\text {eq } j}=\frac{f_{y j}\left(1+\alpha_{j} \mu_{j}-\alpha_{j}\right)}{D_{r j}} .
$$




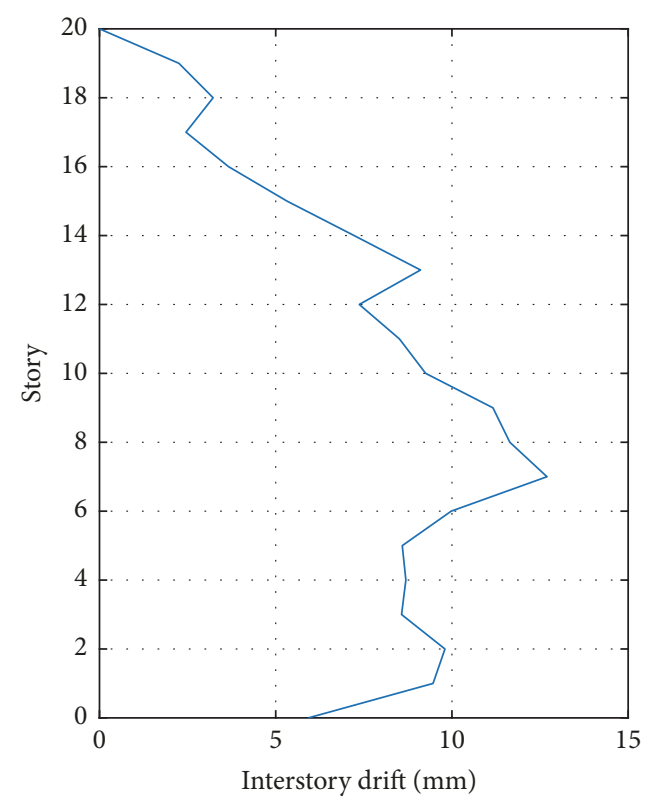

Figure 15: Peak interstory drifts.

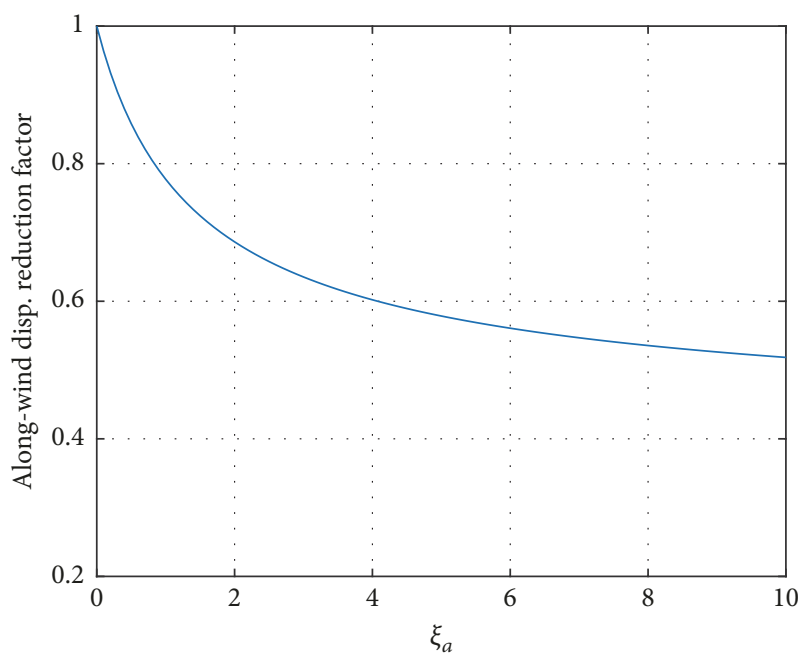

FIGURE 16: Reduction ratio of the fluctuation component in the gust factor.

$\sum W_{j}$ shall be taken by following equation, using the sum of the work done during one complete cycle by the $j$ th damper.

$$
\sum_{j=1}^{N_{d}} W_{j}=\sum_{j=1}^{N_{d}} 4\left(D_{r j} \cdot f_{y j}-D_{y j} \cdot f_{y j}\left(1+\alpha_{j} \mu_{j}-\alpha_{j}\right)\right) .
$$

Because $D_{r j}$ is the value obtained for the damper-installed structure, the equivalent damping ratio cannot be explicitly obtained in the preliminary design stage where only the response of a structure without the damper can be used. When $D_{r j}$ of the structure without the damper is used, the corresponding equivalent damping ratio becomes different from the actual value which shall be obtained by using $D_{r j}$ of the structure with the damper.
In this study, when the number of the dampers, the installation location, and the properties of the damper are given, the added damping ratio is estimated by using the wind load reduction factor and the response of a structure without the damper. The wind load reduction factor of a structure without the damper is just 1 , and then the resulting uncontrolled structural response is calculated by just static wind load or generated dynamic wind load. Based on the calculated the response, the equivalent damping ratio added by the damper whose number, location, and the properties are given can be estimated. Obviously, the first estimated damping ratio gives other wind load reduction factors than 1 . And then the structural response of a structure with the dampers is estimated by multiplying the given wind load reduction factor and the uncontrolled response. This procedure is repeated until two damping ratios become the same; one is calculated by the wind load reduction factor itself, and the other one is based on the structural response obtained by multiplying the wind load reduction factor and the uncontrolled response. Figure 18 shows the damper installation configuration. Totally, 18 dampers are installed at the 1st, $2 \mathrm{nd}$, and 3rd floors. In this section, yield strength $f_{y}=50 \mathrm{kN}$, initial stiffness $k_{d 1}=50 \mathrm{kN} / \mathrm{mm}$, and postyield stiffness $k_{d 2}$ $=10 \mathrm{kN} / \mathrm{mm}$ were used for modeling the hysteresis of the LRB shown in Figure 10. Figure 19 shows the damping ratio added by installing the 18 dampers. Two damping ratios, which are previously mentioned, are compared. The cross point corresponds to $4.22 \%$ damping ratio and 0.596 wind load reduction factor.

Nonlinear time history analysis using the generated wind loads shown in Figure 14 was conducted to calculate the actual response reduction by the damper installation. Figure 20 shows the comparison between uncontrolled and controlled roof displacement. The average response reduction ratios in the floor displacement and interstory drift are, respectively, 0.585 and 0.525 , which are close to the wind load reduction factor 0.596 estimated in the preliminary design. This indicates that the proposed method can be effectively used for estimating the effect of the MHD. Figure 21 shows the hysteretic curve of the MHD installed at the first floor. The MHD shows bilinear behavior and the peak displacement of the MHD is smaller than $5 \mathrm{~mm}$ and the force is smaller than $80 \mathrm{kN}$, which is appropriate for the assumption that only the LRB of the MHD plays a role of dissipating energy when the maximum force does not reach the friction force.

\section{Application of the MHD for Seismic Design}

5.1. Structural Outline. A 15-story reinforced concrete apartment building is considered for verifying the seismic response control performance of the MHD. The structure has the dimensions of $48.6 \mathrm{~m}$ (length) $\times 14.8 \mathrm{~m}$ (width) $\times 45 \mathrm{~m}$ (height) as shown in Figure 22. The gravity load is resisted entirely by the moment frame and the lateral load is resisted by the shear walls in core. The structure with the MHD is designed based on the $75 \%$ base shear force of the structure without the MHD. Beams, columns, and walls are modeled by nonlinear elements using PERFORM 3D program [19]. The 

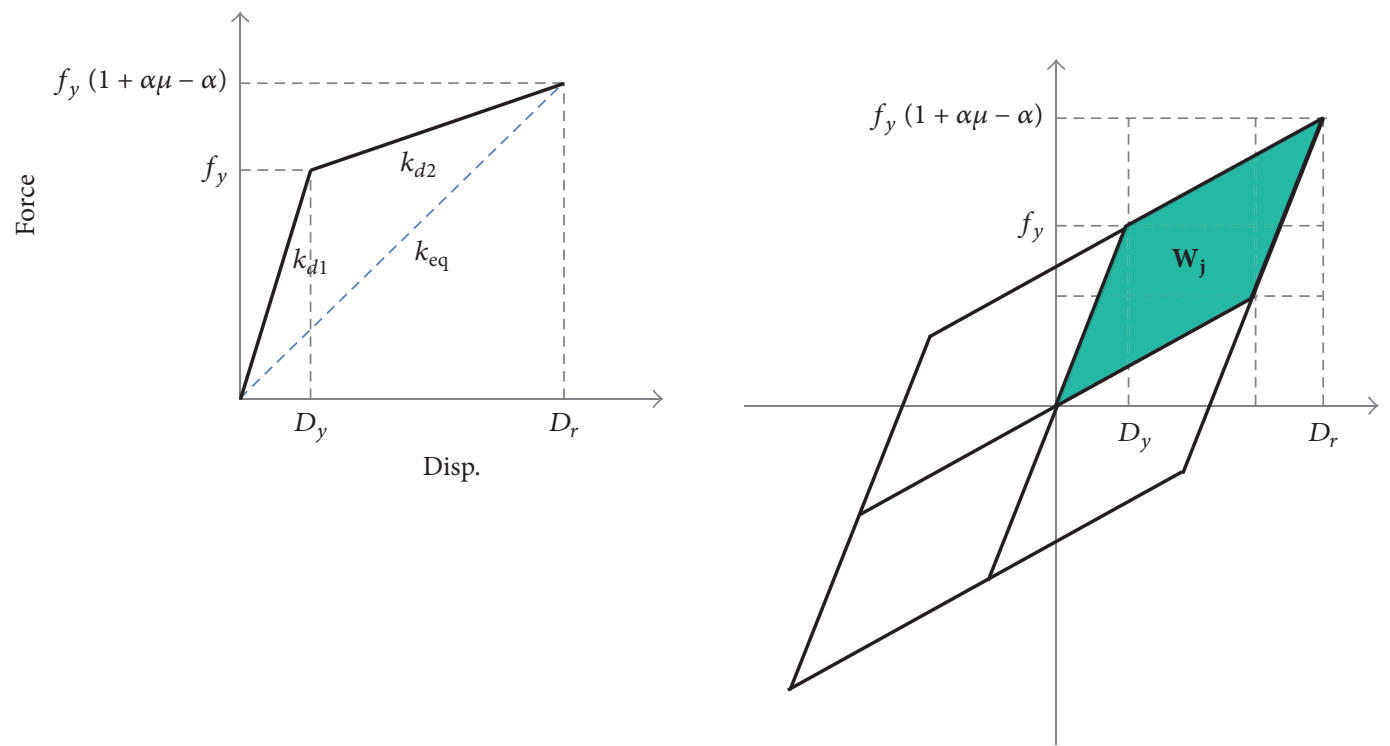

FIgURE 17: Bilinear idealization of the hysteretic curve of the MHD for small deformation.

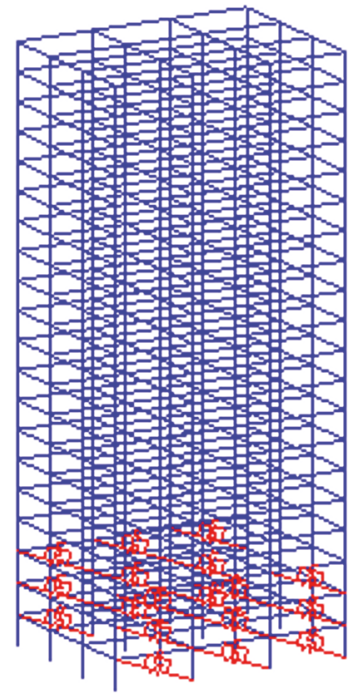

FIGURE 18: Damper installation configuration in a 20-story steel structure.

structure without the dampers is designed according to KBC2016 [15].

5.2. Damper Installation and Nonlinear Analysis. The slip load of friction pad and hysteresis of the LRB (initial stiffness and yield strength) can be adjusted according to the demand by changing the material properties. The $110 \mathrm{kN}$ MHD are installed on the 3rd, 9th, and 15th floors. Yield strength $f_{y}=80 \mathrm{kN}$, initial stiffness $k_{d 1}=50 \mathrm{kN} / \mathrm{mm}$, and postyield stiffness $k_{d 2}=1 \mathrm{kN} / \mathrm{mm}$ were used for modeling the hysteresis of the LRB. And slip load of friction pad was $110 \mathrm{kN}$. Four MHDs at each floor are inserted between the moment frame and shear wall at the location shown in Figure 22. The total summation of the damper friction force is $1,320 \mathrm{kN}(110 \mathrm{kN} \times$

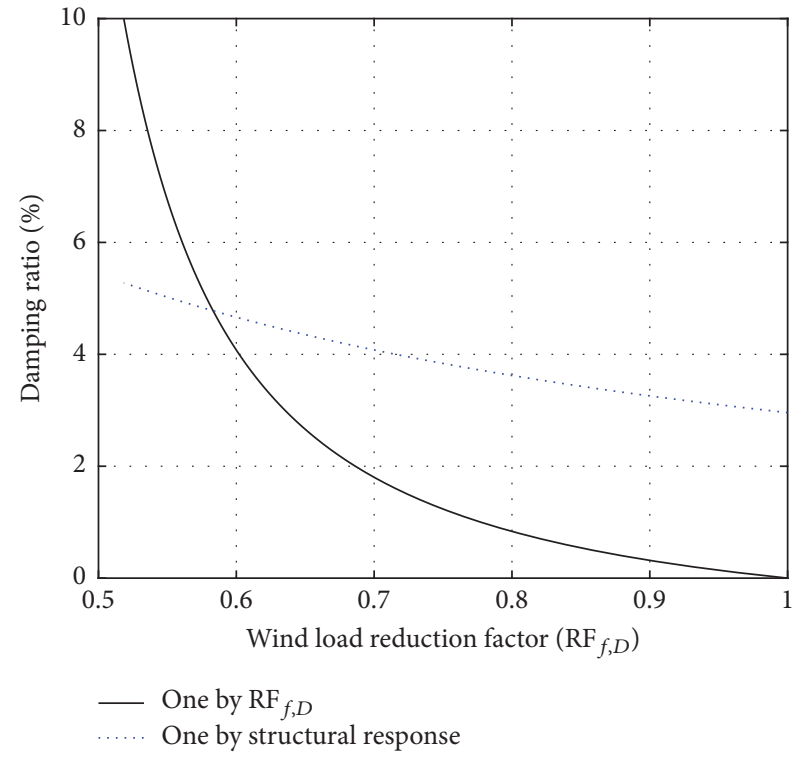

FIGURE 19: Added damping ratio and wind load reduction factor.

3 stories $\times 4$ dampers) and this is about $10 \%$ of the base shear force.

Fourteen ground accelerations measured from three earthquakes were used for numerical analyses. The earthquakes records are Loma Prieta (1989), Chi-Chi (1999), and Cacaeli (1999). The magnitude of the earthquake records was scaled according to the design spectrum presented by Korean Building Code (KBC2016). Figure 23 shows that the peak displacement, drift ratio, and story shear force could be reduced significantly by applying the MHD to the 15-story building structure. Figure 24 illustrates the hysteretic curves of the LRB, the friction pad, and the combined MHD located on the 15 floor when Chi-Chi earthquake load was used as ground acceleration. LRB showed bilinear hysteresis and the 


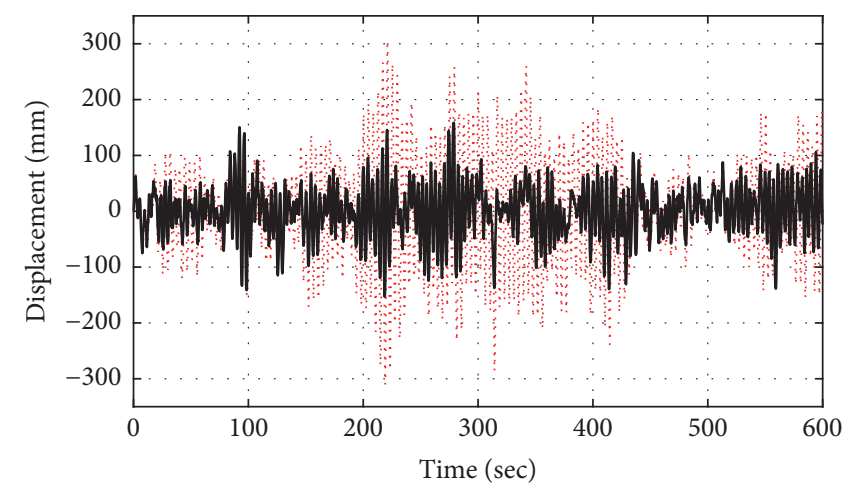

Controlled

FIGURE 20: Roof floor displacement.

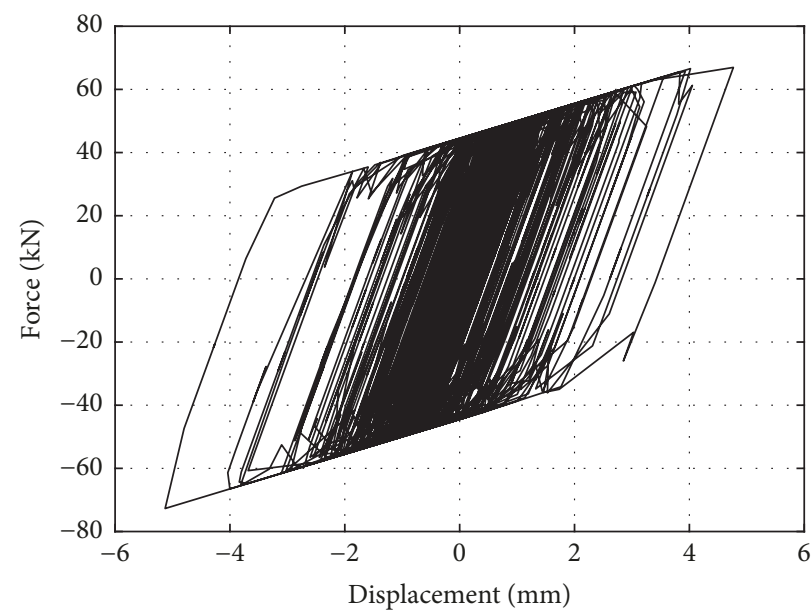

Figure 21: Hysteretic curve of a MHD installed at the first floor.

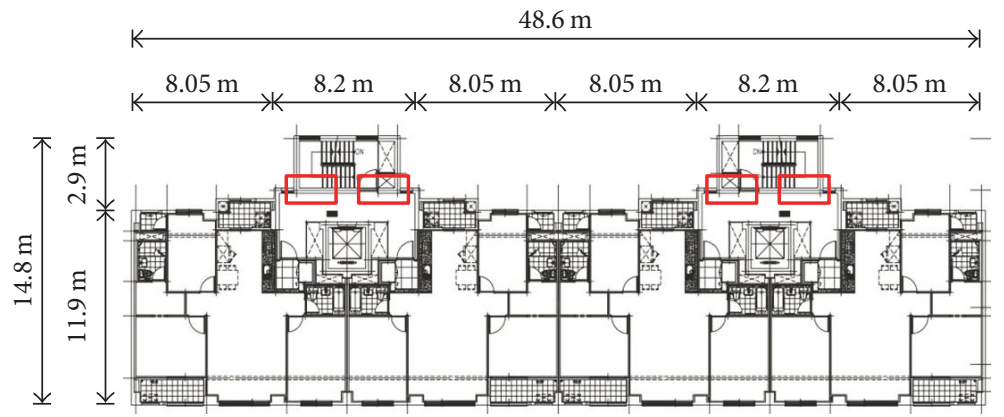

FIGURE 22: A 15-story apartment RC structure and damper installation location.

friction pad slipped at $110 \mathrm{kN}$, and the combined hysteresis of the MHD was trilinear. It is observed that the MHD shows similar behaviors to the experimentally obtained hysteresis shown in Figure 11.

\section{Conclusions}

In this study, a multiaction hybrid damper (MHD) composed of friction pads, lead rubber bearings, and steel plates was proposed. Full scale cyclic tests were conducted for identifying the hysteretic characteristics of the MHD. The test results indicate that only lead rubber bearing initially deforms until the restoring force of the MHD reaches the slip load of the friction pad because the lead rubber bearing and the friction pad are in series connection. After the slippage of the friction pad, the additional deformation in the direction of the increasing displacement of the MHD concentrates on the friction pad. Consequently, the MHD shows independent behaviors of the lead rubber bearing and the friction pad 

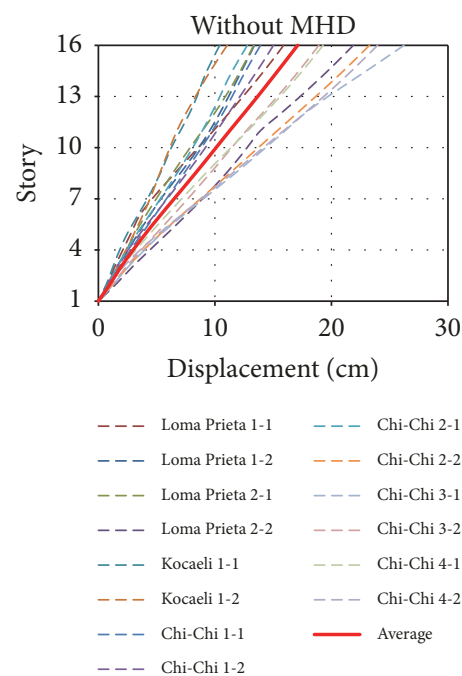

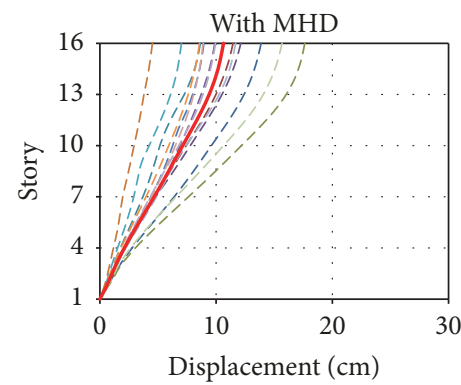

$$
\begin{array}{llll}
--- & \text { Loma Prieta 1-1 } & --- & \text { Chi-Chi 2-1 } \\
--- & \text { Loma Prieta 1-2 } & --- & \text { Chi-Chi 2-2 } \\
--- & \text { Loma Prieta 2-1 } & --- & \text { Chi-Chi 3-1 } \\
--- & \text { Loma Prieta 2-2 } & --- & \text { Chi-Chi 3-2 } \\
--- & \text { Kocaeli 1-1 } & --- & \text { Chi-Chi } 4-1 \\
--- & \text { Kocaeli 1-2 } & --- & \text { Chi-Chi } 4-2 \\
--- & \text { Chi-Chi 1-1 } & &
\end{array}
$$

(a) Peak story displacement
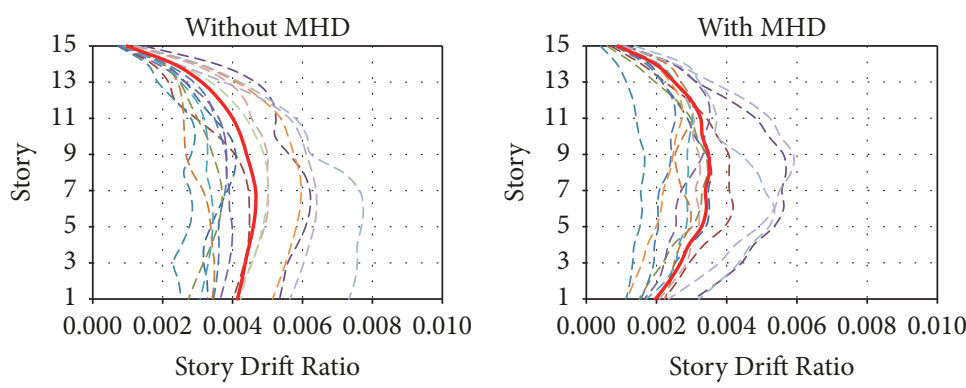

$$
\begin{array}{llll}
--- & \text { Loma Prieta 1-1 } & --- & \text { Chi-Chi 2-1 } \\
--- & \text { Loma Prieta 1-2 } & --- & \text { Chi-Chi 2-2 } \\
--- & \text { Loma Prieta 2-1 } & --- & \text { Chi-Chi 3-1 } \\
--- & \text { Loma Prieta 2-2 } & --- & \text { Chi-Chi 3-2 } \\
--- & \text { Kocaeli 1-1 } & --- & \text { Chi-Chi 4-1 } \\
--- & \text { Kocaeli 1-2 } & --- & \text { Chi-Chi 4-2 } \\
--- & \text { Chi-Chi 1-1 } & \\
--- & \text { Chi-Chi 1-2 } &
\end{array}
$$

$$
\begin{array}{llll}
--- & \text { Loma Prieta 1-1 } & --- & \text { Chi-Chi 2-1 } \\
--- & \text { Loma Prieta 1-2 } & --- & \text { Chi-Chi 2-2 } \\
--- & \text { Loma Prieta 2-1 } & --- & \text { Chi-Chi 3-1 } \\
--- & \text { Loma Prieta 2-2 } & --- & \text { Chi-Chi 3-2 } \\
--- & \text { Kocaeli 1-1 } & --- & \text { Chi-Chi 4-1 } \\
--- & \text { Kocaeli 1-2 } & --- & \text { Chi-Chi 4-2 } \\
--- & \text { Chi-Chi 1-1 } &
\end{array}
$$

(b) Peak story drift ratio
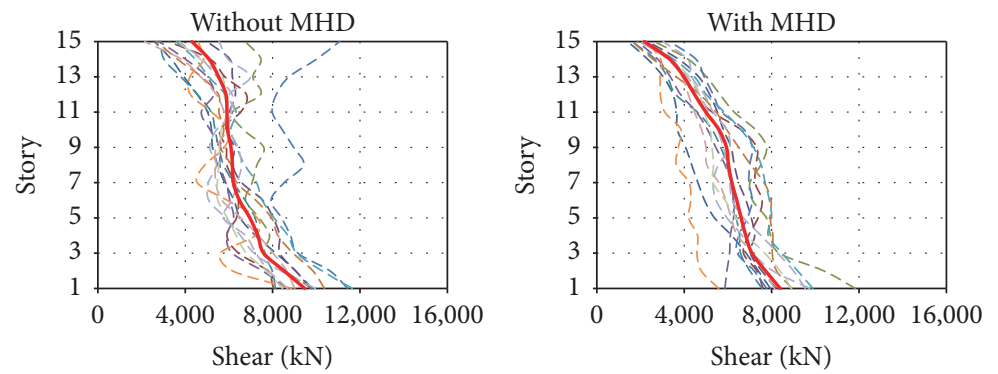

$$
\begin{aligned}
& \text { _ - - Loma Prieta 1-1 _ _ - Chi-Chi 2-1 } \\
& \text { - - - Loma Prieta 1-2 - - } \text { Chi-Chi 2-2 } \\
& \text { - - - Loma Prieta 2-1 _ - - Chi-Chi 3-1 } \\
& \text { _ - - Loma Prieta 2-2 _ _ C Chi-Chi 3-2 } \\
& \text { - - - Kocaeli 1-1 _-- Chi-Chi 4-1 } \\
& \text { _ - - Kocaeli 1-2 _ } \quad \text { - Chi-Chi 4-2 } \\
& \text { - - Chi-Chi 1-1 _ Average } \\
& \text { - - Chi-Chi } 12
\end{aligned}
$$

$$
\begin{array}{llll}
--- & \text { Loma Prieta 1-1 } & --- & \text { Chi-Chi 2-1 } \\
--- & \text { Loma Prieta 1-2 } & --- & \text { Chi-Chi 2-2 } \\
--- & \text { Loma Prieta 2-1 } & --- & \text { Chi-Chi 3-1 } \\
--- & \text { Loma Prieta 2-2 } & --- & \text { Chi-Chi 3-2 } \\
--- & \text { Kocaeli 1-1 } & --- & \text { Chi-Chi 4-1 } \\
--- & \text { Kocaeli 1-2 } & --- & \text { Chi-Chi 4-2 } \\
--- & \text { Chi-Chi 1-1 } & - & \text { Average } \\
--- & \text { Chi-Chi 1-2 } &
\end{array}
$$

(c) Peak story shear force

FIGURE 23: Response comparison between structures with/without MHD. 


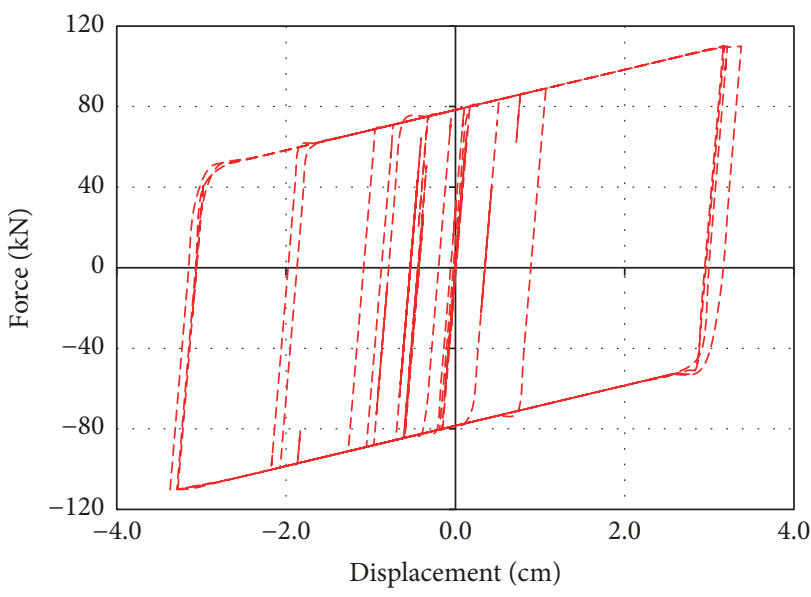

(a) Lead rubber bearing

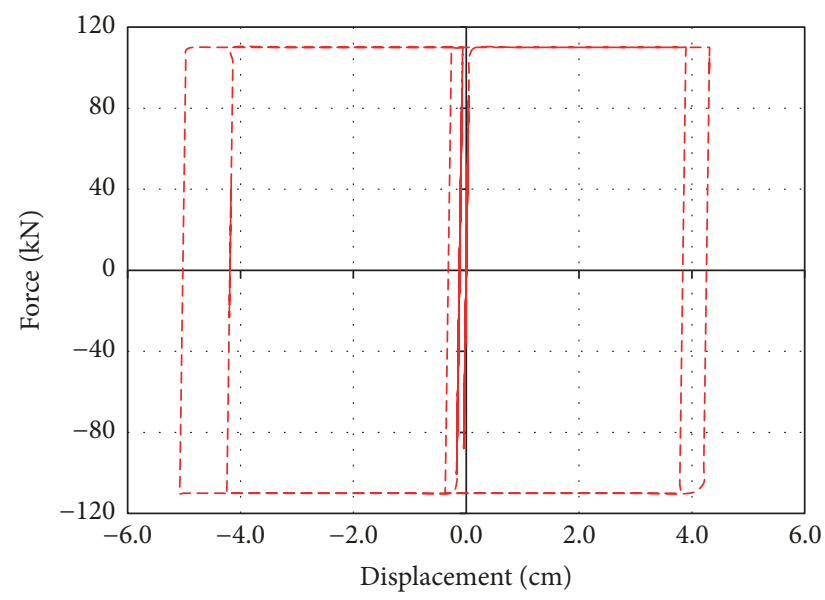

(b) Friction pad

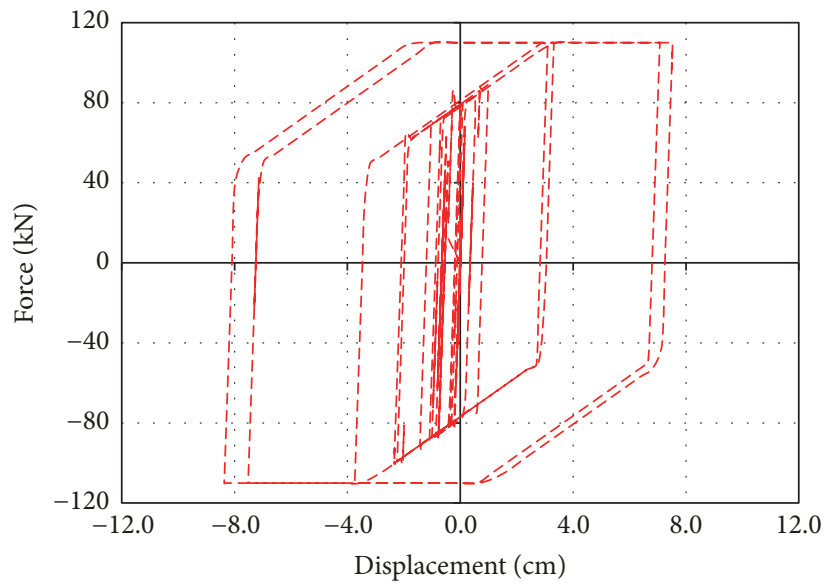

(c) MHD

FIGURE 24: Hysteresis behavior from nonlinear analysis.

according to the amplitude of the deformation. The proposed MHD showed very stable hysteretic behaviors and any undesirable variation of the hysteretic curve in the progress of the cyclic loading was not observed. Numerical analyses results from a 20-story steel structure and 15-story RC apartment structure showed that the proposed MHD can be used for mitigating both the relatively small wind-induced and the relatively large seismically induced responses.

\section{Conflicts of Interest}

The authors declare that they have no conflicts of interest.

\section{Acknowledgments}

This work was supported by the National Research Foundation of Korea (NRF) grant funded by the Korea government (MSIP) (no. NRF-2015R1A2A1A10054506).

\section{References}

[1] D. M. Bergman and S. C. Goel, "Evaluation of cyclic testing of steel plate devices for added damping and stiffness," Report no. UMCE87-10. Ann Arbor (MI,USA): The University of Michigan, 1987.

[2] K.-C. Tsai, H.-W. Chen, C.-P. Hong, and Y.-F. Su, "Design of steel triangular plate energy absorbers for seismic-resistant construction," Earthquake Spectra, vol. 9, no. 3, pp. 505-528, 1993.

[3] T. Kobori, Y. Miura, E. Fukusawa, T. Yamada, T. Arita, and Y. Takenake, "Development and application of hysteresis steel dampers," in Proceedings of the 11th World Conference on Earthquake Engineering, pp. 2341-2346, 1992.

[4] P. W. Clark, I. D. Aiken, F. Tajirian, K. Kasai, E. Ko, and I. Kimura, "Design procedures for buildings incorporating hysteretic damping devices," In: Proc. int. post-SmiRT conf. seminar on seismic isolation. Passive energy dissipation and active control of vibrations of structures, 1999.

[5] A. S. Pall and C. Marsh, "Response of friction damped braced frames," Journal of the Structural Division, vol. 108, no. 6, pp. 1313-1323, 1982.

[6] I. H. Mualla, Experimental and computational evaluation of a novel friction damper device [Ph.D. thesis], Department of Structural Engineering and Materials, Technical University of Denmark, 2000.

[7] T. F. FitzGerald, T. Anagnos, M. Goodson, and T. Zsutty, "Slotted bolted connections in aseismic design for concentrically 
braced connections," Earthquake Spectra, vol. 5, no. 2, pp. 383391, 1989.

[8] A. Filiatrault and S. Cherry, "Seismic design spectra for frictiondamped structures," Journal of Structural Engineering, vol. 116, no. 5, pp. 1334-1355, 1990.

[9] Y. Fu and S. Cherry, "Design of friction damped structures using lateral force procedure," Earthquake Engineering \& Structural Dynamics, vol. 29, no. 7, pp. 989-1010, 2000.

[10] S.-H. Lee, J.-H. Park, S.-K. Lee, and K.-W. Min, "Allocation and slip load of friction dampers for a seismically excited building structure based on storey shear force distribution," Engineering Structures, vol. 30, no. 4, pp. 930-940, 2008.

[11] W. H. Robinson, "Lead-rubber hysteretic bearings suitable for protecting structures during earthquakes," Earthquake Engineering \& Structural Dynamics, vol. 10, no. 4, pp. 593-604, 1982.

[12] J. D. Marshall and F. A. Charney, "A hybrid passive control device for steel structures, I: Development and analysis," Journal of Constructional Steel Research, vol. 66, no. 10, pp. 1278-1286, 2010.

[13] C. Christopoulos and M. Montgomery, "Viscoelastic coupling dampers (VCDs) for enhanced wind and seismic performance of high-rise buildings," Earthquake Engineering \& Structural Dynamics, vol. 42, no. 15, pp. 2217-2233, 2013.

[14] C.-H. Lee, J. Kim, D.-H. Kim, J. Ryu, and Y. K. Ju, "Numerical and experimental analysis of combined behavior of shear-type friction damper and non-uniform strip damper for multi-level seismic protection," Engineering Structures, vol. 114, pp. 75-92, 2016.

[15] KBC2016, Korean Building Code, 2016, Korean Architectural Institute.

[16] Midas Gen Analysis Manual. 2016, Midas IT.

[17] J. C. Wu, J. N. Yang, and W. E. Schmitendorf, "Reducedorder Ho and LQR control for wind-excited tall buildings," Engineering Structures, vol. 20, no. 3, pp. 222-236, 1998.

[18] Building Seismic Safety Council. NEHRP guidelines for the seismic rehabilitation of building. FEMA 273. Washington, DC: Building Seismic Safety Council, 1997.

[19] Perform-3D User Guide: Nonlinear Analysis and Performance Assessment for 3D Structures. 2006, Computers \& Structures Inc. 


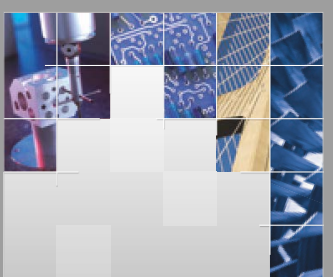

\section{Enfincering}
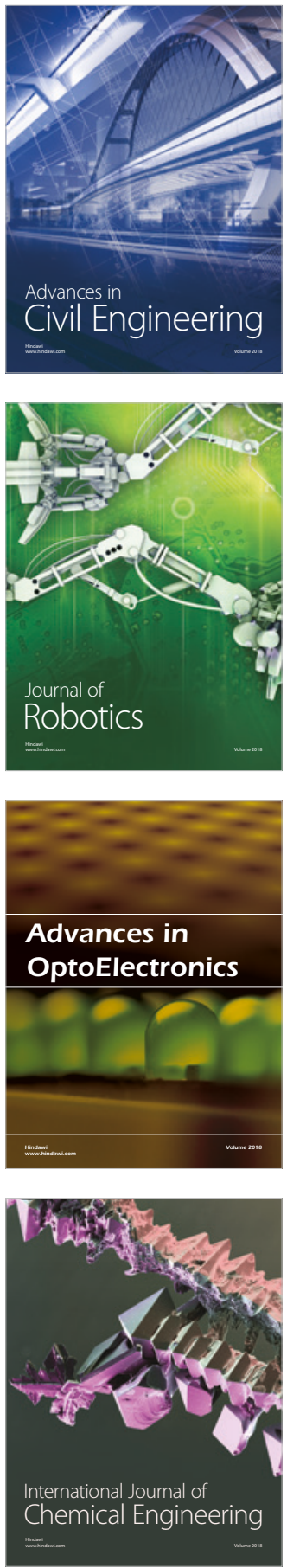

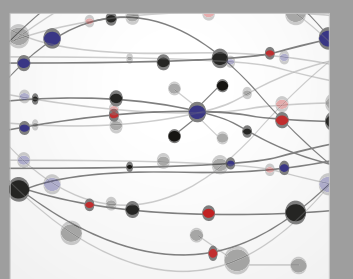

\section{Rotating \\ Machinery}

The Scientific World Journal

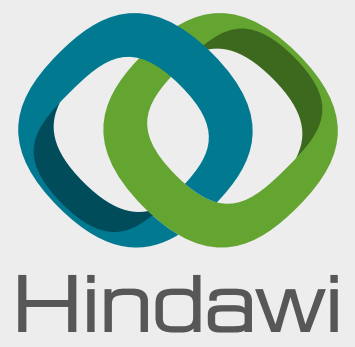

Submit your manuscripts at

www.hindawi.com
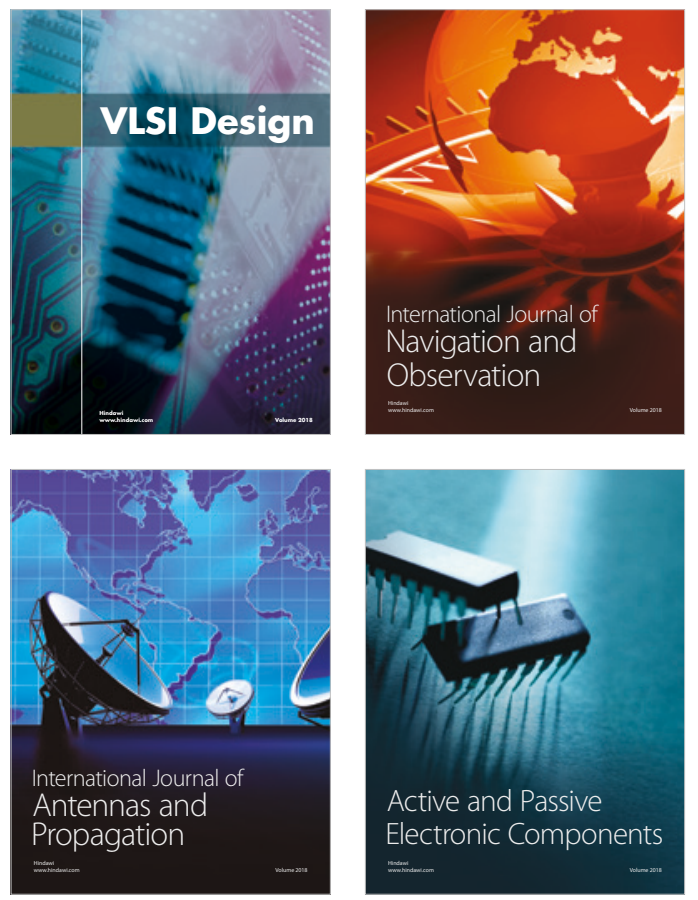
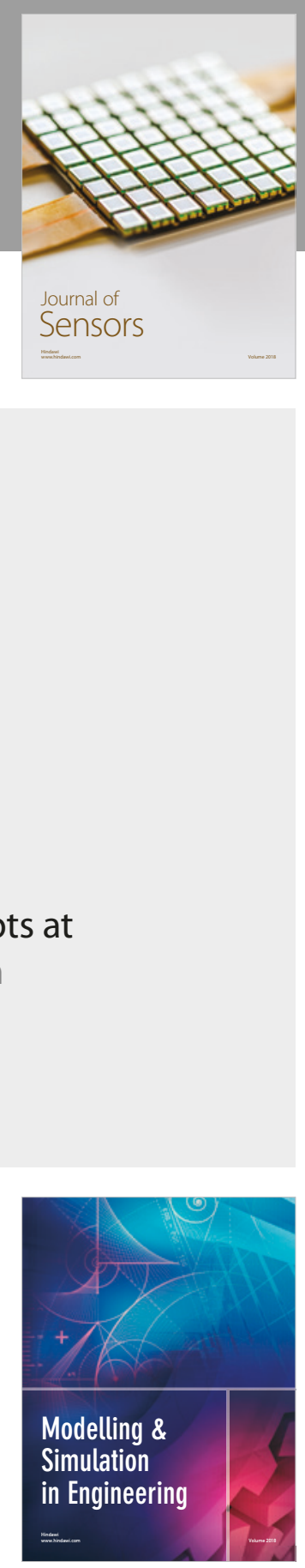

\section{Advances \\ Multimedia}
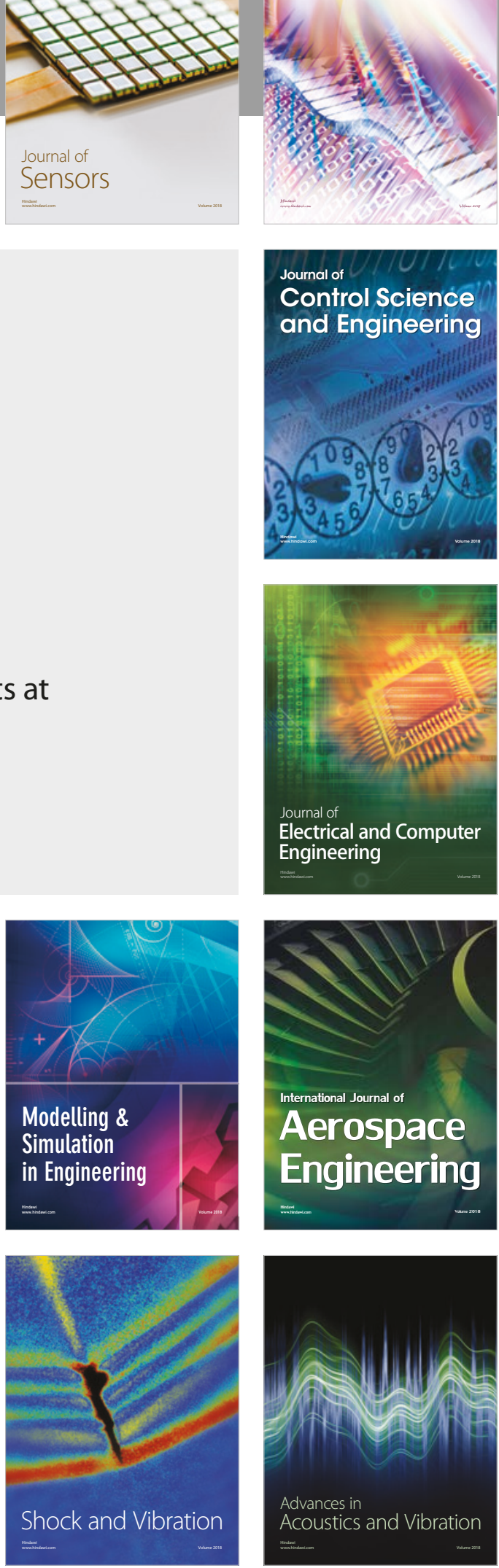